\title{
Awareness and assessment of the Material Safety Data Sheet by dental technicians in Jeju province
}

\author{
Jae-Man Woo ${ }^{1}$, Chan Woo Jo ${ }^{1}$, Se-Hoon Kahm ${ }^{1,2,3}$, Gyeong Pil Moon ${ }^{3}$, Jung Kwan Eun ${ }^{4}$, Sung-Joon Kim ${ }^{1,2,3 *}$
}

${ }^{1}$ Department of Dentistry, Jeju National University Hospital, Jeju, Korea

${ }^{2}$ Department of Dentistry, Jeju National University School of Medicine, Jeju, Korea

${ }^{3}$ Graduate School of Public Health and Welfare, Jeju National University, Jeju, Korea

${ }^{4}$ Jeju National University School of Medicine, Jeju, Korea

The purpose of this study was to investigate the furnishing rate and dental technicians' comprehension level on Material Safety Data Sheet (MSDS) in Jeju province. On-line and off-line questionnaires filled out by 102 dental technicians were acquired and analyzed by frequency analysis, chi-squared test, and one-way ANOVA by SPSS 20.0. On average, respondents rated 3.21 \pm 0.87 on a Likert 5-point scale regarding familiarity with hazardous effects of chemicals, $2.54 \pm 1.09$ to awareness of MSDS, and $2.05 \pm 1.09$ to familiarity with the contents of MSDS. Regarding availability of MSDS or similar information at workplace, $18.6 \%$ responded MSDS were furnished, $5.9 \%$ responded similar information sheets were provided, $29.4 \%$ responded MSDS or similar information sheets were not furnished, and $46.1 \%$ responded that they were not sure. Total of $24.5 \%$ responded positive to availability of MSDS or similar information, which was higher than result from a similar study from 2010 but lower than that of the 2016 study. Gender difference in awareness and comprehension level of MSDS were noted. No statistically significant differences were noted between graduates of Jeju and of other regions regarding awareness and comprehension of MSDS. Position at work rather than length of employment affected level of awareness and comprehension of MSDS. Efforts to rouse dental technicians' interest in chemical safety may enhance workplace health and safety, and there is room for improvement in MSDS provision and education in dental labs of Jeju.

Key Words: Awareness, Dental laboratories, Dental technicians, Material Safety Data Sheets

(c) This is an open-access article distributed under the terms of the Creative Commons Attribution Non-Commercial License (http://creativecommons.org/licenses/by-nc/4.0) which permits unrestricted noncommercial use, distribution, and reproduction in any medium, provided the original work is properly cited.

\section{서 론}

최근 건강과 환경에 대한 관심이 높아지고 있으나, 산업의 발 달에 따라 화학물질의 사용은 증가 추세에 있으며, 위험성이 높 은 화학물질의 사용도 증가되고 있다[1]. 환경부 2017년 5월의 보고에 따르면 '2014년 화학물질 통계조사' 결과 화학물질 취 급업체 22,661개 사업장에서 16,150 종의 화학물질 4억 9,693 만 톤이 유통되었고 2010 년도 대비 제조량은 $11.9 \%$, 수입량은
$27.9 \%$, 수출량은 39.5\%로 각각 증가하여 총 유통량은 $14.9 \%$ 증 가하였다고 한다[2]. 증가된 사용량에 따른 부작용도 적지 않아, 특히 산업안전보건공단의 보고에서는 2014 년 기준으로 근로자 수 30명 미만 제조업의 화학물질 누출로 인한 재해율은 제조업 전체의 $65 \%$ 를 차지하는 것으로 조사되었다. 이는 전체 재해율 의 절반 이상을 소규모 사업장이 차지하는 것으로, 이들 사업장 의 재해율을 낮추기 위한 방안과 안전대책이 시급하다[3].

화학물질의 유해성과 위험성을 명확한 기준에 따라 분류하고

Received July 19 2018; Revised August 15, 2018; Accepted August 22, 2018

Corresponding author: Sung-Joon Kim, Department of Dentistry, School of Medicine, Jeju National University, 15 Aran 13-gil, Jeju 63241, Korea.

Tel: +82-64-717-1843, Fax: +82-64-717-1846, E-mail: samuelsj@jejunu.ac.kr 
알기 쉽게 표시하여 화학물질을 제조, 사용, 취급, 저장 및 운반 하는 근로자와 소비자에게 알리는 것은 근로자와 국민의 건강 과 환경을 보호하고 사고를 미연에 방지하는 데 매우 중요하다 [4]. 그래서 산업안전보건법 제 41조에서는 물질안전보건자료 (Material Safety Data Sheets, MSDS)의 작성과 비치 등에 관하 여 규정하였다. MSDS란 화학물질을 제조, 수입, 사용, 운반, 저 장하는 사업주가 해당 물질에 대한 유해성 평가 결과를 근거로 작성한 자료를 말한다. 근로자에게 위험 또는 건강 장해를 초래 할 우려가 있는 것에 관한 위험성 또는 유해성 등의 정보제공 의 무에 대하여 규정한 것으로, 이를 통해 산업 현장에서 위험 또 는 건강 장해를 방지한다는 목적을 갖고 있다[5]. MSDS는 화학 제품과 회사 정보, 구성 성분 및 함유량, 위험 유해성, 응급 조치 요령, 화재 시 대처방법, 누출 사고 시 대처방법, 취급 및 저장방 법, 노출 방지 및 개인 보호구, 물리적 특성, 안정성 및 반응성, 독성에 관한 정보, 환경에 미치는 영향, 폐기 시 주의사항, 운송 에 필요한 정보, 법 규제 현황, 기타 참고사항 등 총 16 항목으로 구성되어 있다.

하지만, 유기용제나 중금속 등 화학물질은 제조업 사업장에 서 취급되는 것으로만 생각하고 있어, 자신이 사용하고 있는 화 학물질에 대해 잘 모르는 의료계열 근로자들이 $50 \%$ 가 넘는다 고 알려져 있다[6]. 치과 기공물 제작을 주로 행하는 치과기공소 (실)는 소규모 작업장으로 작업 환경이 열악한 경우가 많고 금, 합금, 도재 세공과 연마에 따른 많은 분진, 주물 작업 관련 고온 의 열 발생, 세척을 위한 산 증발과 접착을 위한 유기용제의 사 용 등 많은 많은 건강 위해 요소들이 상존한다. 특히 소환(burn out), 주조(casting) 및 산 세척(pickling)시에 유해가스와 고온 의 증기가 발생하고, 연마 작업 시 분진이 발생하며, 연마 과정 중에 발생되는 니켈 크롬 합금, 치과용 수지(acrylic resin), 석 고, 도재의 분진 농도는 threshhold limit value를 초과하는 경 우도 있는 것으로 보고되었다[7]. 치과기공소(실) 환경의 니켈 농도가 높을수록 재채기, 숨가쁨, 오한, 발열, 관절 및 근육 통 증, 기억력 장애, 우울증 증상이 통계적으로 유의한 증가를 보였 고, 크롬의 농도가 높을수록 숨가쁨, 안구염증 및 눈의 피로, 오 한, 발열, 관절 및 근육통증, 기억력 장애, 우울증 증상에서 통계 적으로 유의한 증가를 보였다[7]. 다른 보고에 따르면 치과 재료 의 취급과 관련된 노출로 피부질환 발생 및 눈 손상, 그리고 천 식이 보고되었으며[8], 특히 치과에서 사용하는 재료 중 메타크 릴레이트(methacrylate)는 사용자에게 알레르기성 접촉 피부염 과 천식을 유발하고 천식의 위험성은 다른 직업 종사자에 비해 치과 종사자에게 크게 증가한다고 하였다[9].

치과계의 발전에 비해 현재의 치과기공소(실)는 여전히 영세 성을 면치 못하고 있어 작업환경이나 치과기공사의 건강 관리 가 소홀하게 다루어지고 있다[7]. 또한 치과기공소(실) 근로자와
사업주의 안전보건에 대한 인식 부재 및 관리 미비로 MSDS를 인지하지 못할 가능성이 높다. 대부분의 치과기공소(실)의 경우 일반 제조업 사업장과는 다른 측면에서 안전보건 관리가 이루 어져 왔으며, 이로 인하여 안전보건 관리 감독에 있어 소홀한 면 이 있었던 것이 사실이다. 이러한 산업안전보건에 대한 무관심 은 치과기공소(실)의 경영자와 근로자들로 하여금 안전보건에 대한 인식을 낮게 하는 원인이 되었다고 할 수 있다[4]. 5인 미만 사업장이 대부분이었던 치과기공소(실)가 최근 기공 장비의 다 양화, 조직화에 따라 규모가 커지고 근무 기공사도 늘어나면서, 삶의 질과 관련하여 근무 환경에 대한 관심이 높아지는 것은 당 연한 일이다. 이를 뒷받침하듯 화학물질 정보제공에 대해 필요 하다고 응답한 비율이 $92.2 \%$ 로 나타날 정도로 치과기공사들의 관심이 높았다[4].

선행 연구에 따르면 수도권 및 충청지방의 치과기공사 231명 을 대상으로 한 설문조사에서 치과기공소(실)에서 사용하는 화 학물질이 인체에 유해하다고 생각하는가에 대한 질문에, 많이 유해하다고 응답하거나 유해하다고 응답한 비율이 $95.6 \%$ 로 대 부분의 치과기공사가 작업 시 사용되는 화학물질이 인체에 유 해한 영향을 미친다고 생각하는 것으로 나타났고, 다양한 재료 를 사용하여 치과 보철물을 제작, 가공하는 치과기공사들의 작 업 특성상 유해 화학 물질에 많이 노출되어 있으나, 치과기공 사들이 MSDS에 대해 잘 알지 못하고 MSDS의 비치 여부를 모 르는 비율도 $49.8 \%$ 에 달했다[4]. 다른 연구에서는 치과기공소 (실)내의 작업 중 피해 발생에서 MSDS 비치 여부와 교차 분석한 결과 $\mathrm{MSDS}$ 를 비치한 그룹에서는 작업으로 인한 피해 있음이 $37.8 \%$ 였으나 MSDS를 비치하지 않은 그룹에서는 피해 있음이 $65.7 \%$ 로 더 높게 나타났으며 이는 유의한 차이가 있어, MSDS 비치를 통해 어느 정도의 재해를 예방할 수 있다고 하였다[10]. 이런 배경 하에서, 지역적 특수성을 지닌 제주 지역 치과기공사 의 MSDS에 관한 실태와 인식도의 분석을 통해 유해 화학 물질 노출 환경 개선, 산업 재해와 직업병 예방 등의 긍정적인 변화를 위한 기초 자료로 활용하고자 한다.

\section{대상 및 방법}

\section{연구 대상}

연구 대상자는 2017년 하반기 제주 치과기공사 협회 등록 회원 총 136명을 대상으로 하였다. 본 연구는 2017년 9월 제주 대학교 생명윤리심의위원회의 승인을 받아 진행되었다(JJNUIRB-2017-023). 자료 수집을 위해 설문지 작성 전 연구의 목적 과 방법 등 연구 진행과 관련된 설명을 제공하였고 연구 참여는 자발적으로 동의한 대상자에 한해 진행되었다. 
제주 지역 소재 1 개 치과기공소 20 명을 대상으로 구글 온라 인 설문지로 예비조사를 시행하여 명확한 문항으로 수정·보완 하였다. 본 설문은 2017년 11월 7일부터 2018년 1월 31일까지 시행하였으며, 자료수집을 위해 제주 치과기공사 협회의 협조 를 얻어 구글 온라인 설문 링크를 배포하였고, 온라인 설문이 어 려운 대상자는 각 근무지에 방문 또는 정기 보수교육 강연장에 서 서면으로 설문조사를 실시하였다. 설문 대상자 중 105명이 응답하였고, 불완전한 응답이 포함된 3건을 제외한 102 명의 설 문 응답을 분석에 사용하였다.

\section{자료 수집 및 설문지 구성}

본 연구에서 사용된 설문지는 Bae의 선행 연구 $[4,10]$ 에 사용 된 설문지를 실정에 맞게 수정·보완하여 구성하였다. 문항의 구 성은 응답자의 일반적 특성 10 문항, 화학물질 정보 인식 관련 4 문항, 화학물질 관리와 예방교육 관련 문항 6문항, 화학물질 유 해성과 정보 제공 필요성 관련 7문항 등 총 27 문항으로 구성되 었다.

일반적 특성은 성별, 연령, 학력, 근무 경력, 직위, 직장 종류, 직장의 규모, 근무시간, 휴식 시간, 졸업대학 소재지에 관한 문 항으로 이루어졌다. 화학물질 정보의 인지도와 정보 제공의 필 요성 등에 관련된 문항은 '전혀 모른다' 또는 '전혀 필요없다'(1 점)에서 ‘자세히(정확히) 알고 있다' 또는 '아주 필요하다'(5점) 의 Likert 5점 척도를 이용하였다. 화학물질 관련 교육 여부와 의향에 대한 문항에는 '교육 받음', 또는 '교육 받지 않음' 중 하 나를 선택하여 응답하도록 하였다. 화학물질 정보에 대한 교육 이 이뤄지는 경로와 관심분야, 화학물질로 인한 다빈도 손상 등 에 관련된 문항은 각 답지를 선택하도록 하였다. 화학물질 정보 에 대한 인식 관련 4 항목의 Cronbach $\alpha=0.813$, 화학 물질 관리 와 예방 교육에 대한 5 문항의 Cronbach $\alpha=0.892$ 로 나타났다.

\section{통계자료 분석}

인구사회학적 특성, MSDS와 관련 자료 비치 여부, 화학물질 정보에 대한 교육이 이뤄지는 경로와 관심분야, 화학물질로 인 한 다빈도 손상 등에 관련된 문항은 빈도분석을 실시하였다. 성 별과 면허 취득학교 소재지에 따른 예방교육 현황과 화학물질 피해 경험에 대한 분석을 위해 교차 분석을 시행하였고, 화학 물질 정보 관련 인식도에 대한 분석을 위해 독립표본 t-test와 one-way ANOVA를 시행하였다. 연구를 위한 통계분석은 IBM SPSS Statistics ver. 20.0 (IBM Co., Armonk, NY, USA)을 이용 하였고, 통계적 유의수준은 $p<0.05$ 으로 설정하였다.

\section{결 과}

설문 응답자 102 명의 일반적 특성은 Table 1 에 나타나 있 다. 성별은 남자가 80 명(78.4\%), 여자 22명(21.6\%)이었다. 응 답자의 연령 분포는 21세에서 62세에 이르렀고, 평균 38.0세 였다. 최종 학력은 전문대학(2-3년제) 졸업이 91명(89.2\%), 대

Table 1. Sociodemographic characteristics of respondents

\begin{tabular}{|c|c|c|}
\hline Characteristic & Classification & Data \\
\hline Total & & $102(100)$ \\
\hline \multirow[t]{2}{*}{ Sex } & Male & $80(78.4)$ \\
\hline & Female & $22(21.6)$ \\
\hline \multirow[t]{3}{*}{ Age (y) } & $\leq 31$ & $37(36.3)$ \\
\hline & $32-43$ & $34(33.3)$ \\
\hline & $\geq 44$ & $31(30.4)$ \\
\hline \multirow[t]{3}{*}{ Education background } & College (2-3 y) & $91(89.2)$ \\
\hline & University (4 y) & $9(8.8)$ \\
\hline & Graduate school & $2(2.0)$ \\
\hline \multirow[t]{3}{*}{ Career $(y)$} & $\leq 7$ & $32(31.4)$ \\
\hline & $8-15$ & $39(38.2)$ \\
\hline & $\geq 16$ & $31(30.4)$ \\
\hline \multirow[t]{2}{*}{ Type of workplace } & Dental laboratory & $90(88.2)$ \\
\hline & Dental clinic & $12(11.8)$ \\
\hline \multirow[t]{3}{*}{ Office hours } & $<8$ & $17(16.7)$ \\
\hline & $8-10$ & $45(44.1)$ \\
\hline & $>10$ & $40(39.2)$ \\
\hline \multirow[t]{3}{*}{ Rest time per day (min) } & $<30$ & $38(37.3)$ \\
\hline & $30-60$ & $47(46.0)$ \\
\hline & $>60$ & $17(16.7)$ \\
\hline \multirow[t]{2}{*}{ Region of licensure } & Jeju & $51(50.0)$ \\
\hline & Other regions & $51(50.0)$ \\
\hline \multirow{3}{*}{$\begin{array}{l}\text { Size of dental laboratory } \\
\text { (number of workers) }\end{array}$} & $<5$ & $26(25.5)$ \\
\hline & $5-24$ & $34(33.3)$ \\
\hline & $\geq 25$ & $42(41.2)$ \\
\hline \multirow[t]{3}{*}{ Position in the workplace } & Owner or chief & $31(30.4)$ \\
\hline & Team manager & $27(26.5)$ \\
\hline & General technician & $44(43.1)$ \\
\hline
\end{tabular}

Values are presented as number (\%). 
학(4년제) 졸업이 9명 $(8.8 \%)$, 대학원 이상이 2명 $(2.0 \%)$ 으로 나 타났다. 경력은 평균 12.7 년이었으며, 근무연차 단위로 7년 이 하가 32명(31.4\%), 8년에서 15년이 39명(38.2\%), 16년 이상이 31 명(30.4\%)이었으며, 직장유형은 독립 개설된 치과기공소 근 무자가 90명(88.2\%)으로 치과 병-의원 내에 개설된 치과기공 실 12 명 $(11.8 \%)$ 보다 많은 것으로 나타났다. 1 일 근무시간은 평 균 10.3 시간으로 응답했다. 8 시간 이하 17 명 $(16.7 \%), 8$ 시간 초 과 10 시간 이하가 45 명(44.1\%), 10 시간 초과 40 명(39.2\%)이었 고, 하루 근무 시간 중 평균 휴식 시간에 대한 응답은 평균 55.4 분으로 응답했으며, 30 분 이하 38 명(37.3\%), 30분 초과 60 분 이하 47명(46.1\%), 60분 초과 17명(16.7\%)순으로 나타났다. 면 허 취득 학교 소재지는 제주도 내 51명(50.0\%), 제주도 외 지역 51명(50.0\%)으로 같았다. 직장 규모는 5인 미만 소규모 사업장 소속이 26명(25.5\%), 5인에서 25인 미만 사업장 소속이 34명 (33.3\%), 25인 이상 사업장 소속이 42명(41.2\%)으로 나타났다. 직위는 소장 또는 실장 31 명(30.4\%), 팀장 27 명(26.5\%), 일반 기사 44 명(43.1\%)이었다.

화학물질이 건강에 미치는 영향과 MSDS에 대한 인식 정도 에 대한 결과는 Table 2에 나타나 있다. 화학물질이 건강에 미

Table 2. Awareness of potential health hazard of chemicals and the contents of Material Safety Data Sheets (MSDS)

\begin{tabular}{lc}
\hline \multicolumn{1}{c}{ Awareness } & Score \\
\hline Awareness of potential health hazards of chemicals & $3.21 \pm 0.87$ \\
Awareness of the presence of MSDS & $2.54 \pm 1.09$ \\
Awareness of the contents of MSDS & $2.05 \pm 1.09$ \\
\hline
\end{tabular}

Values are presented as mean \pm standard deviation.

${ }^{\mathrm{a}} 5$-point Likert scale.
치는 영향에 대한 5점 척도 응답은 3.21 ( \pm 0.87$)$ 로 나타났으며, $\mathrm{MSDS}$ 에 대해서 알고 있는지는 2.54 ( \pm 1.09$)$, 구성하는 내용을 알고 있는지는 $2.05( \pm 1.09)$ 로 나타났다.

치과기공소(실)에 MSDS나 화학물질 정보가 담긴 자료가 비 치되어 있는지에 대한 2010년 결과와 2016년 타 지역 대상 조 사의 비교표는 Table 3에 나타나 있다. 본 연구에서 MSDS가 비 치되어 있다는 응답이 19명(18.6\%), MSDS는 없으나 비슷한 자 료가 있다는 응답이 6명(5.9\%), 비치되어 있지 않다는 응답이 30 명(29.4\%)이었고, 모른다는 응답도 47명(46.1\%)으로 나타났 다. MSDS 또는 그와 유사한 자료 비치 응답 합이 24.5\%이었고, 이는 타 연구의 2010년 조사에 비해서는 높았으나 2016년 조사 보다는 낮았다.

화학물질로 인한 손상과 관련 화학물질 정보 교육 관련 문항 에 대한 응답은 Table 4와 같다. 기공 업무 중 화학물질로 인한 직업병이나 피해 등 건강 영향을 겪은 응답자는 42 명(41.2\%)이 었다. 가장 빈번한 피해 요인은 각종 금속과 석고연마 시의 분 진 흡입 40명(39.2\%)이었으며, 레진 작업 중 휘발성 물집 흡입 과 맨손 작업에 의한 피부질환이 각각 25 명 $24.5 \%)$ 로 뒤를 이 었다. 화학물질에 대한 정보를 잘 얻지 못한다는 응답자가 68 명 (66.7\%), 보관용기의 경고 표시를 통해 정보를 얻는 경우가 15 명(14.7\%), 기공소장 또는 실장과 치과기공사 협회나 학회에서 얻는 경우가 각각 8 명 $(7.8 \%)$ 으로 뒤를 이었다. 화학물질 정보에 대한 교육을 받을 의향이 있는 응답자는 82 명(80.4\%)으로 나타 났으며, 가장 관심 높은 정보는 화학물질이 인체에 미치는 영향 (41.2\%), 사용하는 화학물질의 종류와 특성 $(22.5 \%)$, 노출 시 응 급조치(19.6\%), 취급 및 저장 방법(13.7\%), 폐기방법(2.9\%) 순 이었다.

응답자의 성별과 치과기공사 면허 취득 학교 소재지를 독립 변수로 한 화학물질 피해 경험과 예방관리 현황에 대한 교차분

Table 3. Availability of Material Safety Data Sheets (MSDS) or similar information sheets in dental laboratories (comparison among 2010, 2016, and 2018 Jeju regional data)

\begin{tabular}{lccc}
\hline \multicolumn{1}{c}{ Availability of MSDS } & \multicolumn{2}{c}{ Report } \\
\cline { 2 - 4 } & $\mathbf{2 0 1 8}$ & $\mathbf{2 0 1 6}$ & $\mathbf{2 0 1 0}$ \\
\hline Furnished of MSDS & $19(18.6)$ & $22(21.2)$ & $0(0.0)$ \\
Not furnished of MSDS, but similar information provided & $6(5.9)$ & $15(14.4)$ & $40(17.3)$ \\
Not furnished & $30(29.4)$ & $37(35.6)$ & $76(32.9)$ \\
I don't know & $47(46.1)$ & $30(28.8)$ & $115(49.8)$ \\
Total & $102(100.0)$ & $104(100.0)$ & $231(100.0)$ \\
\hline
\end{tabular}

Values are presented as number (\%).

Report of 2016: An HJ, et al. (J Korean Acad Dent Technol 2016;38:209-216) [10].

Report of 2010: Bae EJ. (J Korean Acad Dent Technol 2010;32:221-232) [4]. 
Table 4. Incidence of chemical damage or injury, and education on management of chemicals

\begin{tabular}{|c|c|}
\hline $\begin{array}{l}\text { Injury or damage from chemicals and back- } \\
\text { ground of education }\end{array}$ & Data $(n=102)$ \\
\hline \multicolumn{2}{|l|}{$\begin{array}{l}\text { Injury or damage from the use of chemicals } \\
\text { during work }\end{array}$} \\
\hline Yes & $42(41.2)$ \\
\hline No & $60(58.8)$ \\
\hline \multicolumn{2}{|l|}{$\begin{array}{l}\text { The most frequent injury or damage from the } \\
\text { use of chemicals }\end{array}$} \\
\hline Respiration of metal- or stone-containing dust & $40(39.2)$ \\
\hline $\begin{array}{l}\text { Respiration of highly volatile liquid such as } \\
\text { resin monomer }\end{array}$ & $25(24.5)$ \\
\hline Skin diseases from working bare-hand & $25(24.5)$ \\
\hline $\begin{array}{l}\text { Respiration of noxious gas from burn-out } \\
\text { procedure }\end{array}$ & $6(5.9)$ \\
\hline Vision disturbances & $5(4.9)$ \\
\hline Joint disorders such as neck and back & $1(1.0)$ \\
\hline \multicolumn{2}{|l|}{$\begin{array}{l}\text { Means of education on potential hazards of } \\
\text { chemical substances }\end{array}$} \\
\hline No information was provided & $68(66.7)$ \\
\hline Warning labels on chemical containers & $15(14.7)$ \\
\hline Dental laboratory owner/manager & $8(7.8)$ \\
\hline $\begin{array}{l}\text { Korean Dental Technologist Association or } \\
\text { Korean Academy of Dental Technology }\end{array}$ & $8(7.8)$ \\
\hline $\begin{array}{l}\text { Ministry of Employment and Labor or Korea } \\
\text { Occupational Safety and Health Agency }\end{array}$ & $3(2.9)$ \\
\hline \multicolumn{2}{|l|}{$\begin{array}{l}\text { Willingness on learning about chemicals infor- } \\
\text { mation }\end{array}$} \\
\hline Yes & $82(80.4)$ \\
\hline No & $20(19.6)$ \\
\hline \multicolumn{2}{|l|}{$\begin{array}{l}\text { The most valuable contents among information } \\
\text { on chemical materials }\end{array}$} \\
\hline Health hazards of chemicals & $42(41.2)$ \\
\hline $\begin{array}{l}\text { Types and characteristics of chemicals used } \\
\text { during work }\end{array}$ & $23(22.5)$ \\
\hline $\begin{array}{l}\text { Emergency protocols following exposure to } \\
\text { hazardous chemicals }\end{array}$ & $20(19.6)$ \\
\hline Management and storage of chemicals & $14(13.7)$ \\
\hline Waste disposal of chemicals & $3(2.9)$ \\
\hline
\end{tabular}

Values are presented as number (\%).
석 결과는 Table 5 와 같다. 화학물질이 인체에 미치는 영향 및 위험성에 대한 교육 여부에 대한 응답은 성별에 따른 통계적 차 이를 보였으며, 노출 시 응급조치에 대한 교육 여부는 경계역 $(p=0.065)$ 을 보였고, 그 외 교육 경험과 화학물질 피해 여부에 대한 분포 차이는 통계적으로 유의하지 않았다. 제주지역과 제 주 외 지역으로 분류한 면허 취득 학교소재지에 따른 문항별 응 답 분포차이는 통계적으로 유의하지 않았다.

응답자 성별과 치과기공사 면허 취득 학교 소재지에 대한 화 학물질 정보 관련 인식도에 대한 분석 결과는 Table 6과 같다. $\mathrm{MSDS}$ 의 인지도와 MSDS를 구성하는 내용에 대한 응답에서 남 자 기공사의 인지도가 통계적으로 유의하게 높게 나타났다. 그 외 화학물질의 건강 영향과 인체 유해성, 정보제공의 필요성과 손상 예방에 도움이 될 것이라는 항목에는 통계적으로 유의한 차이를 나타내지 않았다. 면허 취득학교 소재지에 따른 문항에 서는 모든 항목에서 통계적으로 유의한 평균 차이를 나타내지 않았다.

경력과 지위를 3 그룹으로 구별하여 화학물질 정보 관련 인 식 정도를 분석한 결과는 Table 7과 같다. 경력에 따른 MSDS에 인식에 대한 응답은 통계적으로 경계역 $(p=0.067)$ 을 보였으나, 모든 항목에서 통계적으로 유의한 차이를 나타내지 않았다. 직 위에 따른 항목별 분석에서 화학물질에 대한 정보가 담겨있는 MSDS 인식과 구성하는 내용 인식 응답에서 통계적으로 유의한 평균 차이를 보였으며, 두 항목 모두 소장(또는 실장)이 가장 높 았고 일반 기사가 낮게 나타났다.

Table은 제시되지 않았지만 같은 항목에 대한 5인 미만, 5-24 인, 25 인 이상의 직장 규모별 분석에서는 통계적으로 유의한 차 이가 나타나지 않았다.

\section{고 찰}

산업안전보건법 제 41 조에 의하여 화학물질이나 화학물질을 함유한 제제를 제조, 수입, 사용, 운반 저장하는 사업주는 MSDS 를 비치하여야 한다. 이에 한국산업안전공단은 1997년부터 화 학물질을 취급하는 중소규모 사업장에 대하여 노동부의 산업 안전보건법, 환경부의 유해화학물질관리법 등에서 규정한 물질 30,000 종에 대하여 안전지침을 제공하기 시작하였다[3]. 법적 인 규제에도 불구하고 근로자들의 MSDS에 대한 인식과 이해도 는 높지 않은 편인데 외국의 경우 평균적으로 근로자들은 MSDS 정보의 약 3 분의 2 정도만을 이해 및 파악하고 있다고 하였고 [11], 우리나라는 외국의 자료를 한글로 번역하는 과정에서 단 어의 일관성 부족으로 더 낮을 수 있다고 하였다[12].

치과기공사들의 건강관리 실태 및 인식수준에 관한 연구[13] 에서 치과기공소(실)에 대해 가장 먼저 개선해야 할 것이 작업 
Table 5. Incidence of chemical damage or injury, and education on management of chemicals by gender and region of licensure

\begin{tabular}{|c|c|c|c|c|c|}
\hline \multicolumn{3}{|c|}{ Sex } & \multicolumn{3}{|c|}{ Region of licensure } \\
\hline Male $(n=80)$ & Female $(n=22)$ & $\chi^{2} / p$-value & Jeju $(n=51)$ & $\begin{array}{c}\text { Other regions } \\
\quad(n=51)\end{array}$ & $\chi^{2} / p$-value \\
\hline \multicolumn{6}{|c|}{ and characteristics of chemicals } \\
\hline $15(18.8)$ & $3(13.6)$ & $0.310 / 0.757$ & $9(17.6)$ & $9(17.6)$ & $0.000 / 1.000$ \\
\hline $65(81.3)$ & $19(86.4)$ & & $42(82.4)$ & $42(82.4)$ & \\
\hline
\end{tabular}

Education on dangers and health hazards of chemicals

\begin{tabular}{|c|c|c|c|c|c|c|}
\hline Yes & $15(18.8)$ & $0(0.0)$ & $4.836 / 0.037^{\star}$ & $7(13.7)$ & $8(15.7)$ & $0.078 / 1.000$ \\
\hline No & $65(81.3)$ & $22(100.0)$ & & $44(86.3)$ & $43(84.3)$ & \\
\hline
\end{tabular}

Education on emergency protocols upon exposure to hazardous chemicals

$\begin{array}{ccccrrr}\text { Yes } & 13(16.3) & 0(0.0) & 4.097 / 0.065 & 7(13.7) & 6(11.8) & 0.088 / 1.000 \\ \text { No } & 67(83.8) & 22(100.0) & & 44(86.3) & 45(88.2)\end{array}$

Education on management and storage of chemicals

$\begin{array}{lrrrrrr}\text { Yes } & 17(21.3) & 4(18.2) & 0.099 / 1.000 & 12(23.5) & 9(17.6) & 0.540 / 0.625 \\ \text { No } & 63(78.8) & 18(81.8) & & 39(76.5) & 42(82.4)\end{array}$

Education on chemical waste disposal

$\begin{array}{lrrrrrr}\text { Yes } & 10(12.5) & 1(4.5) & 1.135 / 0.449 & 6(11.8) & 5(9.8) & 0.102 / 1.000 \\ \text { No } & 70(87.5) & 21(95.5) & & 45(88.2) & 46(90.2)\end{array}$

Previous injury or damage from chemicals at work

\begin{tabular}{llllll} 
Yes & $31(38.8)$ & $11(50.0)$ & $0.902 / 0.342$ & $19(37.3)$ & $23(45.1)$ \\
No & $49(61.3)$ & $11(50.0)$ & & $32(62.7)$ & $28(54.9)$ \\
\hline
\end{tabular}

Values are presented as number $(\%)$.

${ }^{\star}$ Statistically significant by chi-square test.

Table 6. Awareness of potential health hazard of chemicals and comprehension level of Material Safety Data Sheets (MSDS) by gender and region of licensure

\begin{tabular}{|c|c|c|c|c|c|c|}
\hline \multirow[b]{2}{*}{ Awareness and comprehension level } & \multicolumn{3}{|c|}{ Sex } & \multicolumn{3}{|c|}{ Region of licensure } \\
\hline & Male $(n=80)$ & Female $(n=22)$ & $p$-value & Jeju $(n=51)$ & $\begin{array}{l}\text { Other } \\
\text { regions } \\
(n=51)\end{array}$ & $p$-value \\
\hline Awareness of potential health hazards of chemicals & $3.27(0.90)$ & $3.01(0.74)$ & 0.227 & $3.24(0.91)$ & $3.19(0.84)$ & 0.778 \\
\hline Awareness of the presence of MSDS & $2.73(1.09)$ & $1.82(0.75)$ & $0.000^{* * *}$ & $2.38(0.98)$ & $2.70(1.18)$ & 0.141 \\
\hline Comprehension of the contents of MSDS & $2.73(1.29)$ & $1.76(0.92)$ & $0.000^{* * *}$ & $2.43(1.26)$ & $2.62(1.31)$ & 0.442 \\
\hline Awareness in health hazards of chemicals & $1.99(1.11)$ & $1.91(1.23)$ & 0.752 & $4.33(0.89)$ & $4.31(0.81)$ & 0.908 \\
\hline Recognition on the need for information on chemicals & $4.10(0.81)$ & $4.36(0.73)$ & 0.173 & $4.16(0.84)$ & $4.16(0.76)$ & 0.984 \\
\hline $\begin{array}{l}\text { Effectiveness of provision of information in prevention } \\
\text { of accidents from chemical use }\end{array}$ & $3.60(0.79)$ & $3.86(0.35)$ & 0.131 & $3.61(0.78)$ & $3.71(0.67)$ & 0.497 \\
\hline
\end{tabular}

***Statistically significant by $\mathrm{t}$-test. 
Table 7. Awareness of potential health hazard of chemicals and comprehension level of Material Safety Data Sheets (MSDS) by length of employment and position at workplace

\begin{tabular}{|c|c|c|c|c|c|c|c|c|c|}
\hline \multirow[b]{2}{*}{$\begin{array}{l}\text { Awareness and comprehen- } \\
\text { sion level }\end{array}$} & \multirow[b]{2}{*}{$\begin{array}{c}\text { Total } \\
(n=102)\end{array}$} & \multicolumn{4}{|c|}{ Career $\left(y^{*}\right)$} & \multicolumn{4}{|c|}{ Position in the workplace } \\
\hline & & $\begin{array}{c}\leq 7 \\
(\mathbf{n}=32)\end{array}$ & $\begin{array}{c}8-15 \\
(n=39)\end{array}$ & $\begin{array}{c}\geq 16 \\
(n=31)\end{array}$ & $p$-value & $\begin{array}{l}\text { General } \\
\text { technician } \\
(\mathrm{n}=44)\end{array}$ & $\begin{array}{c}\text { Team } \\
\text { manager } \\
(\mathbf{n}=27)\end{array}$ & $\begin{array}{l}\text { Owner } \\
\text { or chief } \\
(n=31)\end{array}$ & $p$-value \\
\hline $\begin{array}{l}\text { Awareness of potential health } \\
\text { hazards of chemicals }\end{array}$ & $3.21(0.87)$ & $3.13(0.84)$ & $3.21(0.85)$ & $3.31(0.94)$ & 0.714 & $3.01(0.78)$ & $3.33(0.85)$ & $3.39(0.98)$ & 0.128 \\
\hline $\begin{array}{l}\text { Awareness of the presence of } \\
\text { MSDS }\end{array}$ & $2.54(1.09)$ & $2.23(0.94)$ & $2.53(1.05)$ & $2.86(1.22)$ & 0.067 & $2.16(0.83)^{\mathrm{a}}$ & $2.59(1.09)^{\mathrm{ab}}$ & $3.02(1.24)^{\mathrm{b}}$ & $0.002^{* *}$ \\
\hline $\begin{array}{l}\text { Comprehension of the } \\
\text { contents of MSDS }\end{array}$ & $2.52(1.28)$ & $2.27(1.21)$ & $2.53(1.23)$ & $2.78(1.40)$ & 0.280 & $2.10(1.00)^{\mathrm{a}}$ & $2.59(1.20)^{\mathrm{ab}}$ & $3.06(1.51)^{\mathrm{b}}$ & $0.005^{\star *}$ \\
\hline $\begin{array}{l}\text { Awareness in health hazards } \\
\text { of chemicals }\end{array}$ & $4.32(0.85)$ & $4.31(0.90)$ & $4.28(0.92)$ & $4.39(0.72)$ & 0.874 & $4.16(0.81)$ & $4.52(0.89)$ & $4.39(0.84)$ & 0.196 \\
\hline $\begin{array}{l}\text { Recognition on the need for } \\
\text { information on chemicals }\end{array}$ & $4.16(0.80)$ & $4.13(0.81)$ & $4.03(0.93)$ & $4.35(0.55)$ & 0.224 & $4.07(0.86)$ & $4.37(0.63)$ & $4.10(0.83)$ & 0.271 \\
\hline $\begin{array}{l}\text { Effectiveness of provision of } \\
\text { information in prevention of } \\
\text { accidents from chemical use }\end{array}$ & $3.66(0.72)$ & $3.53(0.84)$ & $3.67(0.66)$ & $3.77(0.67)$ & 0.414 & $3.25(0.73)$ & $3.74(0.66)$ & $3.77(0.76)$ & 0.264 \\
\hline
\end{tabular}

${ }^{*} \mathrm{y}$ means year.

** Statistically significant by ANOVA test.

${ }^{\mathrm{a}, \mathrm{b}}$ Same superscript character means statistically same group.

환경(45.8\%)이라고 가장 높게 응답한 것으로 나타나 치과기공 소의 환경 개선 및 예방 대책에 대한 요구가 높은 것을 볼 수 있 다. 이에 따라서 제주 지역 치과기공사들에 대한 MSDS에 대한 인식을 높이고 MSDS를 비치함으로써 안전한 근무 환경을 조 성하고 화학물질로 인한 사고를 미연에 방지하는데 기여하고자 인식 정도와 실태 조사를 위해 본 연구를 실시하였다.

본 연구에서 치과 기공 업무 중 화학물질로 인한 직업병이나 피해 경험을 가진 비율이 이미 $41.2 \%$ 로 나타났다. 이러한 비율 은 예방과 교육을 통해 감소할 수 있을 것이며, 반대로 적절한 개입이 없으면 그 비율이 증가되어 근무 환경의 위험요소가 될 것이다. 화학물질이 건강에 미치는 영향에 인지도는 5점 척도 3.21 ( \pm 0.87 )이었으나, $\mathrm{MSDS}$ 에 대해 알고 있는지는 2.54 ( \pm 1.09)로 상대적으로 낮았으며, MSDS를 구성하는 내용에 대해 서는 2.05 ( \pm 1.09 )로 가장 낮았다. 타 지역의 2016년 보고[10] 에서는 화학물질이 건강에 미치는 영향과, MSDS에 대해 알고 있는 5점 척도 평균이 각각 2.86과 2.30으로 본 연구보다는 평 균치가 높았다. 이러한 실태는 건강에 대한 직접적인 영향에 관 해서는 상대적으로 더 많이 알고 있으나 MSDS에 관한 인식도는 낮다는 것과, 이에 대한 대책이 필요하다는 것을 의미한다.

화학물질에 관한 교육 내용 일부와 MSDS 인지 여부 및 MSDS 를 구성하고 있는 내용에 대한 항목에서는 남녀 차이가 있는 부
분이 있었는데, 이러한 성별차이가 나타난 것은 남녀의 치과 기 공 작업 과정에서의 역할의 상대적 차이가 있는 관행과 이에 따 른 관심도의 차이에 따른 결과라 추정해 볼 수 있다.

치기공(학)과 출신학교 지역을 제주 지역(단일 대학 학과 소 재)과 외부로 분류하여 대학 교육 과정에 따른 영향을 알아보고 자 하였다. 분석 결과에서 지역에 따른 통계적 차이는 보이지 않 았다. 각각의 학과 교육 과정의 차이가 있을 수 있으나 통계적 차이가 없는 것으로 보아, MSDS 등 화학 물질 관련 교육에 대한 부분은 실무 과정에서 더 필요하고 의미가 있다고 해석해 볼 수 도 있으며, 치기공(학)과 교육 과정에서도 이러한 내용의 교육 필요성을 검토해 볼 필요가 있다.

경력 차이와 작업장에서의 지위에 따른 분석에서는, 연차에 따른 경력 차이는 보이지 않았으나, 지위에 따른 MSDS의 인식 과 구성 내용의 인지도의 차이를 보였고, 소장 또는 실장이 일 반기사보다 높은 인지도를 보이는 것으로 나타났다. 이는 단순 하게 경력이 축적되어 관련 사항을 알게 되는 것이 아니라, 작 업장에서 관리 역할에 따라 취급하는 물품과 재료 등에 대한 관 심이 높아짐에 따른 것으로 보인다. 타 문헌의 MSDS 인지 정도 에 영향을 미치는 요인 분석에서는 근무기간, 직종, 안전 보건 교육 경험, 화학물질 교육 필요성, MSDS 이용경험, MSDS가 비 치되었을 때 유의한 결과가 나타났다[14]. 즉 근무기간이 길수 
록 MSDS 인지 정도가 높았고, 간호사 그룹이 임상병리사 그룹 보다 인지 정도가 높았다. 그리고 안전 보건교육 경험이 많을수 록, 화학물질 교육 필요성이 높을수록, MSDS 이용 경험이 많을 수록, MSDS가 비치되었을 때 인지 정도가 높았다[14]. 같은 연 구에서 근무기간별 차이는 없었으나 직위별로는 차이를 보였는 데, 본 연구와도 일치하는 결과이다.

같은 연구에 따르면 병원근무자 $94.2 \%$ 가 화학물질 관련 교육 이 필요하다고 하였지만 $47.9 \%$ 만이 안전 보건교육을 해마다 정 기적으로 받고 있으며, MSDS를 부서에 비치하는 비율은 $78.4 \%$ 이었고, $\mathrm{MSDS}$ 를 쉽게 접근할 수 있는 경우가 $28.9 \%, \mathrm{MSDS}$ 를 쉽게 이해하는 병원 근무자는 $23.2 \%$ 에 불과했다[14]. 의무 사항 을 규정한 2주기 의료기관 인증 평가를 통과한 600 병상 이상의 의료기관 근무자 대상 조사는 MSDS가 비치되어 있다( $78.4 \%)$, 비치되어 있지 않다(10.0\%), 모르겠다(11.6\%)로 나타났다[14]. 그러나 소규모 사업장 중심인 치과기공소의 경우는 MSDS 비치 율이 높지 않다는 결과들이 보고되었다. 2010년에 수도권과 충 청권의 치과기공사를 대상으로 조사된 연구[4]에서는 MSDS에 대해 자세히 알고 있다고 응답한 비율이 3.0\%로 매우 낮은 수 준이었으나, 2016년 경기도 치과기공사 대상 연구[10]에서는 $12.5 \%$ 로 약간 높아졌다. 치과기공소(실) 내 MSDS 비치 여부에 대해서도 2010년 연구[4]에서는 비치되어 있다고 응답한 비율 이 $0.0 \%$ 였으나, 2016년에는 $21.2 \%$ 가 비치되어 있다고 응답하 였고 $14.4 \%$ 가 유사한 자료를 비치하고 있다고 응답하였다. 본 연구대상인 제주에서는 $18.6 \%$ 가 비치되어 있다고 응답하였고 $5.9 \%$ 가 유사한 자료를 비치하고 있다고 하여, 2010년 보고[4] 보다는 높은 비치율을 보였으나 2016년 보고[10]보다는 낮은 비율을 보이고 있었다. 지역적 특성을 고려할 때, 제주 지역은 관련 교육이나 행정 지도를 통해 타 지역에 비해 적은 투자로 더 개선된 결과를 얻을 수 있을 것으로 예상된다.

치과기공소(실) 내에 MSDS의 비치율은 과거에 비해 높아졌 으며, MSDS에 대한 인식도 지속적으로 증가할 것이다. 대한치 과기공사협회와 기공학회에서는 보수교육이나 다양한 매체를 통해 치과기공사들에게 MSDS에 대한 홍보와 교육을 하고 있으 며, 이를 통해 인식도가 제고될 것으로 생각해 볼 수 있으나, 연 구 결과 협회와 학회를 통해 교육을 받았다고 응답한 비율은 낮 게 나타남으로써 노력이 아직까지 치과기공사들에게 원활히 전 달되지 않는 것으로 추정하기도 했다[10]. 본 연구에서도 협회 나 학회 또는 고용노동부 등 유관기관에서 관련 정보를 얻었다 는 응답은 $10.7 \%$ 에 불과하여, 좀더 효과적인 홍보와 교육활동 이 필요할 것이다. MSDS는 전문적이며 기술적인 내용으로 구성 되어 있어 관심을 갖지 않으면 다른 교육보다 어렵고 지루하다 는 생각을 가질 수도 있다. 따라서 관심을 가지는 분야를 적절한 교육내용과 방법을 선택, 교육을 실시하는 것이 실효성을 높일
수 있을 것으로 판단된다[15]. Kang[14]은 병원종사자의 MSDS 의 인지에 관한 연구에서 화학물질 교육 필요성이 높을수록, 물 질안전 보건자료 교육 경험이 많을수록 인지도가 높다는 결과 를 바탕으로 각 근무 상황에 맞는 MSDS 관련 교육의 필요성을 강조했다. 2010년 연구[4]에서는 화학물질 정보에 대한 교육을 받을 의향이 $80.5 \%$ 로 나타났고, 2016년 경기 지역 치과기공사 연구에서는 104 명 모두 화학물질에 대한 교육을 받길 희망했으 며, 제주에서도 $80.4 \%$ 의 대상자가 교육받기를 원하여 교육 수 요가 높았다[10].

치과위생사를 대상으로 한 MSDS의 항목별 중요도 조사에서 ‘위해 위험성'이 1 위로 나타났고, 이어 ‘응급조치요령', ‘독성에 관한 정보', ‘노출방지 및 개인보호구’의 순이었다[16]. MSDS의 개선에 대한 필요는 ‘화학물질이 건강에 미치는 영향', '포장 및 용기의 경고표시 부착', '치과재료의 포장에 정보 제공의 필요' 순으로 조사되었다[16]. 본 연구에서는 '위해 영향 및 위험성'이 1위(41.2\%), '작업장 내 화학물질 종류와 특성(22.5\%)', '응급조 치(19.6\%)'로 유사하면서도 직군별 특성을 반영한 결과를 보였 다.

타 업종의 MSDS 교육횟수 보고를 찾아 보면, 화학제품 제조 업은 65\% 이상이 매월 또는 2-3개월에 1회 교육을 실시하는 반 면, 합성수지 플라스틱 제조업은 $73.4 \%$ 가 6개월 또는 12 개월에 1 회 교육을 실시한다고 하였고 기타 업종은 90\% 이상이 6개월 혹은 12 개월에 1회 실시한다고 하였다[15]. 그리고, 근로자들이 받는 MSDS 관련 교육 종류에 대한 보고는 MSDS 내용(80.3\%), 취급 시 주의사항(81.6\%), 건강 유해성(73.7\%) 등은 다른 내용 보다 많은 반면 산업안전보건법(57.9\%)과 경고표지(56.6\%)에 관한 내용은 상대적으로 적은 것으로 알려졌다[15].

화학물질 취급 종사자 대상의 보고에서, MSDS 교육을 받은 근로자들은 교육 경험이 없는 근로자에 비해 MSDS 인식도가 상 대적으로 높았고, 화학물질로 인한 손상 경험 조사 결과 교육을 받은 경험이 있는 근로자보다 그렇지 않은 근로자가 상대적으 로 손상 경험이 많은 것으로 나타났으며 사고 예방 경험 조사 결 과에서는 MSDS 교육은 화학물질로 인한 사고예방에 효과가 있 는 것으로 나타났다[3]. 교육의 효과가 있으므로 사업장 규모를 막론하고 안전을 위한 교육은 반드시 필요하다.

치과기공사에 대한 교육을 통해 MSDS에 대한 인식을 높이고 치과기공소에 $\mathrm{MSDS}$ 를 비치, 참고할 수 있도록 하여 안전한 근 무 환경에서 작업함으로써 산업 재해와 직업병 예방에 기여할 수 있다. 아울러, 제주 지역에서 상대적으로 관심이 낮을 수 있 는 직업 질환에 관련된 위험 요소들을 평가하고, 평소 안전 관리 에 관심을 가질 수 있는 기회가 될 수 있다.

본 연구는 제주 치과기공사를 대상으로 한 지역적으로 한정 된 연구이며, 자기 기입식 설문 응답을 통한 연구이므로 추후 더 
욱 실제적이고 객관적인 현상을 반영한 연구가 필요할 것이다. 본 연구를 통해 작업 환경 개선과 화학물질로 인한 손상 예방을 위한 다양하고 체계적인 교육이 활성화 되기를 기대해 본다.

\section{ACKNOWLEDGEMENTS}

This work was supported by a research grant from the Jeju National University Hospital Research Fund of Jeju National University in 2016.

\section{CONFLICTS OF INTEREST}

No potential conflict of interest relevant to this article was reported.

\section{ORCID}

\author{
Jae-Man Woo \\ https://orcid.org/0000-0001-7209-186X \\ Chan Woo Jo \\ https://orcid.org/0000-0003-4777-0080 \\ Se-Hoon Kahm \\ https://orcid.org/0000-0001-6945-8480 \\ Gyeong Pil Moon \\ https://orcid.org/0000-0002-5946-5836 \\ Jung Kwan Eun \\ https://orcid.org/0000-0002-2437-191X \\ Sung-Joon Kim \\ https://orcid.org/0000-0003-0603-4036
}

\section{REFERENCES}

1. Lee JH, Park JA, Park JB. The effect of OECD activities on chemical management policy. J Nat Sci Soonchunyang Univ 1998;4:129-141.

2. Korea Ministry of Environment. Announced results of domestic chemical substance distribution survey. Sejong: Korea Ministry of Environment; 2017.

3. Hwang SM. A study on the necessity of the awareness and education of Material Safety Data Sheets (MSDS) of chemical substance handlers: focused on small businesses in Chungnam area [Thesis]. Suwon: Graduate School of Construction Engineering and Industry, Kyonggi University; 2017.

4. Bae EJ. The management actual condition and recognition of material data sheets in dental laboratories. J Korean Acad Dent Tech 2010;32:221-232. doi: 10.14347/kadt.2010. 32.3.221.

5. Jeong JW. Material safety data sheets and warning sign. J Korean Ind Health Assoc 2015;332:27-35.

6. Kim EA. Occupational diseases of health care workers. Hanyang Med Rev 2010;30:265-273. doi: 10.7599/hmr.2010. 30.4.265.

7. Song EJ. Working conditions \& health effect to dental technicians [Thesis]. Seoul: Graduate School of Public Health, Yonsei University; 2005.

8. Leggat PA, Kedjarune U, Smith DR. Occupational health problems in modern dentistry: a review. Ind Health 2007; 45:611-621. doi: 10.2486/indhealth.45.611.

9. Jaakkola JJ, Jaakkola MS. Professional cleaning and asthma. Curr Opin Allergy Clin Immunol 2006;6:85-90. doi: 10. 1097/01.all.0000216849.64828.55.

10. An HJ, Tae WB, Oh H, Song MJ, Park CH, Bae EJ. Recognition of the material safety data sheet of dental technicians: focused on Gyeonggi-do dental technicians. J Korean Acad Dent Tech 2016;38:209-216. doi: 10.14347/kadt.2016. 38.3.209.

11. Kolp P, Sattler B, Blayney M, Sherwood T. Comprehensibility of material safety data sheets. Am J Ind Med 1993;23: 135-141. doi: 10.1002/ajim.4700230119.

12. Choi JW. A Study on implementation of MSDS systems \& their promotion. Incheon: Korea Occupational Safety and Health Agency; 2002.

13. Choi UJ. A study on the health management of dental technicians and their awareness of the same. J Korean Acad Dent Tech 2000;22:113-126.

14. Kang SM. A study on the recognition of MSDS(material safety data sheets) for the health professionals [Thesis]. Cheonan: Graduate School of Legal Studies and Public Administration, Dankook University; 2016.

15. Kim KW, Park JW. A surveillance study of the viewpoints on the Material Safety Data Sheets (MSDS) training for safety and health managers and workers. J Korean Soc Occup Environ Hygiene 2012;22:276-283.

16. Oh NR, Kim HK, Cho MJ. The effects of recognition of material safety data sheets in dental hygienist. J Digit Converg 2017;15:215-223. doi: 10.14400/JDC.2017.15.2.215. 